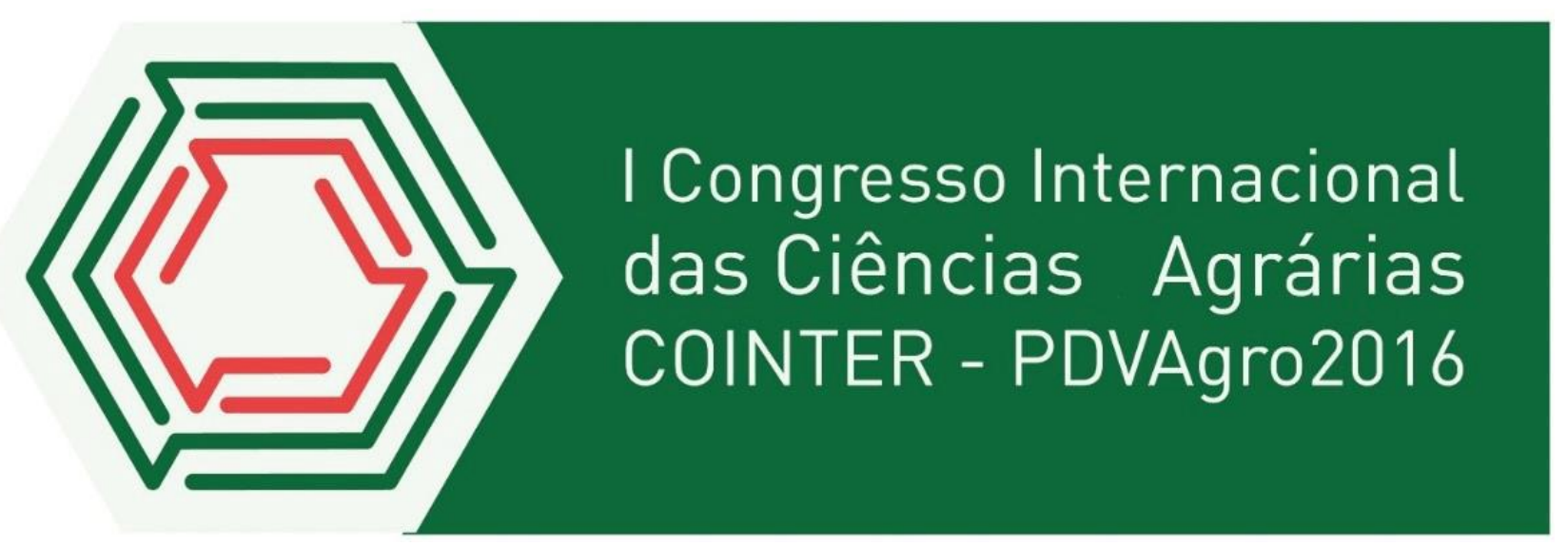

\title{
ACEITABILIDADE DA ALIMENTAÇÃO ESCOLAR OFERECIDA POR UMA ESCOLA DE UMÃS, DISTRITO DE SALGUEIRO - PE
}

\author{
Apresentação: Pôster
}

Rosicláudia Gonçalves Ribeiro' ${ }^{1}$ Carolaine Gomes dos Reis²; Luciana Façanha Marques²

\section{Introdução}

A escola exerce um papel fundamental na formação de hábitos alimentares, pois é nesse ambiente em que crianças e adolescentes passam uma boa parte do seu tempo. Esses espaços devem oferecer uma alimentação equilibrada e orientar seus alunos para a prática de bons hábitos de vida, uma vez que, uma alimentação escolar de qualidade é capaz de melhorar o desempenho dos estudantes, contribuir para sua saúde e nutrição (CONRADO e NOVELLO, 2007).

Segundo o Fundo Nacional de Desenvolvimento da Educação - FNDE, o Programa Nacional de Alimentação Escolar - PNAE, é o responsável pela merenda escolar das escolas públicas dos estados, do Distrito Federal e dos municípios do país. O PNAE além de ter como objetivo atender às necessidades nutricionais dos alunos durante o período em que permanecerem na escola, também contribui para o crescimento, o desenvolvimento, a aprendizagem, o rendimento escolar dos estudantes e a formação de hábitos alimentares saudáveis (FNDE, 2012).

A aceitação da alimentação pelos alunos é um dos principais fatores que determinam a qualidade dos serviços de alimentação escolar. Além disso, evita o desperdício de recursos públicos na compra de gêneros alimentícios rejeitados (CECANE, 2010).

\footnotetext{
${ }^{1}$ Graduanda do Curso de Tecnologia em Alimentos - IF Sertão-PE/Salgueiro, *rosy_claudia97@hotmail.com ${ }^{2}$ Graduanda do Curso de Tecnologia em Alimentos - IF Sertão-PE/Salgueiro, carolainetecalimentos@gmail.com ${ }^{3}$ Docente doutora do Curso de Tecnologia em Alimentos - IF Sertão-PE/Salgueiro, marques.luciana@gmail.com
} 
Diante desses fatores, o objetivo do trabalho foi avaliar a aceitabilidade da alimentação escolar oferecida por uma escola no Distrito de Umãs, no Município de Salgueiro - PE, através de informações fornecidas pelos próprios alunos a partir da aplicação do teste de aceitabilidade.

\title{
Fundamentação Teórica
}

Mas, por que ter como objeto de estudo a merenda escolar, ou melhor, sua aceitação na escola?

Para a escolarização de alunos de classes mais baixas, a merenda é um elemento de grande relevância, pois grande parte desses escolares não tem acesso a uma boa alimentação e a práticas alimentares saudáveis. Muitas vezes, por falta de alimentação em casa, frequentam o ensino público em busca de saciar a fome através da merenda, tornando-a assim um elemento motivador da frequência na escola. Segundo Domingues (2006):

\begin{abstract}
A alimentação saudável, balanceada e nutritiva é um direito de todos, mas devido às necessidades sócio econômicas da população em geral isso nem sempre é possível. Para isso, o ambiente escolar se torna propício para o desenvolvimento de práticas alimentares saudáveis, pois melhora o nível educacional e reduz transtornos de aprendizado causados por deficiências nutricionais, tais como anemia e desnutrição.
\end{abstract}

O PNAE é o programa responsável pela merenda escolar dos estudantes das escolas públicas do país, ele foi implantado em 1955 pelo Ministério da Educação e Cultura - MEC e de acordo com Conrado e Novello (2007), "deve conter alimentos de boa aceitação, visando ao seu aprimoramento e real contribuição para promoção da saúde da criança e do adolescente por meio de ações de educação alimentar e nutricional e da oferta de refeições que cubram as suas necessidades nutricionais durante o período letivo, pois uma criança bem alimentada apresenta maior aproveitamento escolar."

A aceitação de um alimento pelos estudantes é um importante fator para determinar a qualidade do serviço prestado pelas escolas em relação ao fornecimento da alimentação escolar, e segundo o Grupo de Trabalho,

O teste de aceitabilidade é o conjunto de procedimentos metodológicos, cientificamente reconhecidos, destinados a medir o índice de aceitabilidade da alimentação oferecida aos escolares (CECANE, 2010, p.09). 
O teste de aceitabilidade é um instrumento fundamental, pois sua execução é fácil e permite uma verificação da preferência média dos alimentos oferecidos. Existem os modelos de fichas de escala hedônica facial que pode ser utilizada para escolares de $1^{\circ}$ ao $5^{\circ}$ ano; de escala hedônica facial mista que pode ser utilizada para escolares do $4^{\circ}$ ao $5^{\circ}$ ano e de escala hedônica verbal que pode ser utilizada para escolares a partir do $6^{\circ}$ ano.

\section{Metodologia}

O trabalho realizado é de pesquisa quantitativa do tipo exploratório descritivo. A pesquisa foi realizada entre 248 estudantes do $6^{\circ}$ ao $9^{\circ}$ ano do ensino fundamental e do $1^{\circ}$ ao $3^{\circ}$ ano do ensino médio de uma escola estadual localizada no Distrito de Umãs, pertencente ao Município de Salgueiro-PE, no período diurno.

A aplicação do teste foi realizada durante uma semana na escola, onde os alunos avaliaram a aceitação das refeições que eram oferecidas a cada dia dessa semana. Para a avaliação foi feita a escolha por uma ficha dos cinco pontos da escala hedônica verbal (quadro 1), que pode ser utilizada para escolares a partir do $6^{\circ}$ ano, pedindo que respondessem se adoraram, gostaram, indiferente, não gostaram ou se detestaram a alimentação oferecida; e para completar foi apresentada uma pergunta fechada para que apontassem o que mais gostaram ou desgostaram nas preparações oferecidas.

O cardápio oferecido na semana da aplicação do teste de aceitabilidade era constituído por: macarronada com salsicha; cuscuz com frango; achocolatado e pão com ovo; cuscuz com leite e feijoada.

Quadro 1 - Modelo de ficha de escala hedônica verbal que pode ser utilizada para escolares a partir do $6^{\circ}$ ano.

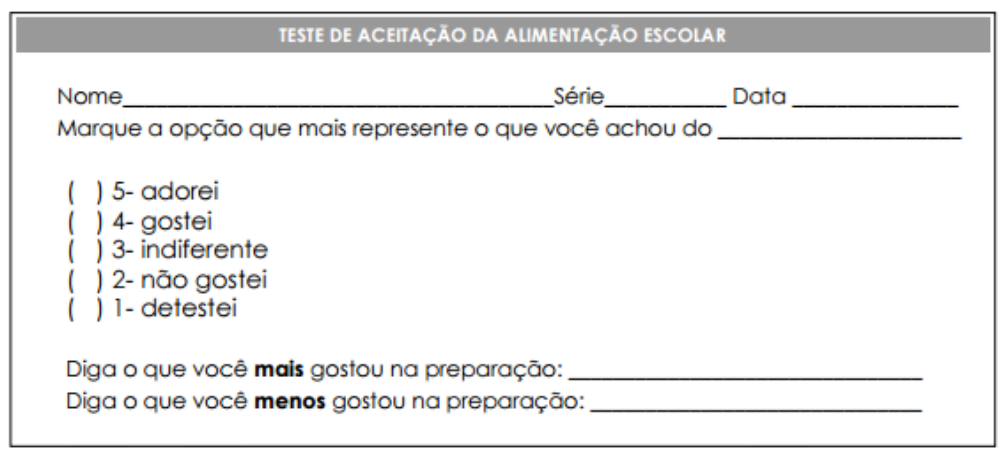

Fonte: Manual para aplicação dos testes de aceitabilidade no Programa Nacional de Alimentação Escolar - PNAE.

Os dados obtidos foram expressos em planilha eletrônica EXCEL® para cálculo das porcentagens de aceitação, e posterior montagem de gráficos explicativos. 


\section{Resultados e Discussões}

Com relação aos alunos do ensino fundamental e do ensino médio que consumiram os alimentos oferecidos, a refeição com maior aceitação em ambas as modalidades de ensino (escolha da alternativa de "adorei”, com 58,5\% e 52,9\% respectivamente) foi a feijoada.

A refeição que obteve uma aceitação deficiente foi o cuscuz com leite, que apresentou 49,3\% (ensino fundamental) 73,9\% (ensino médio) de escolha do item "detestei".

Figura 1 - Porcentagem da aceitação da feijoada. Fonte: Própria

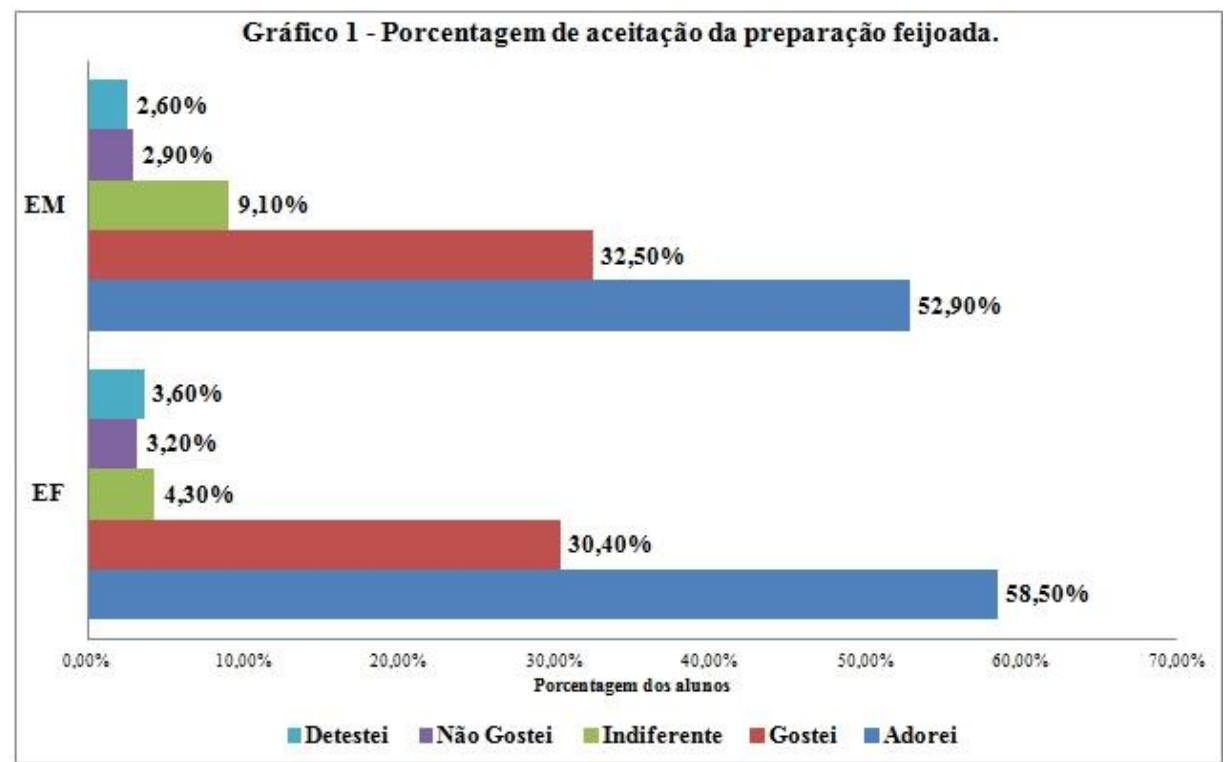

Figura 2 - Porcentagem de aceitação do cuscuz com leite. Fonte: Própria

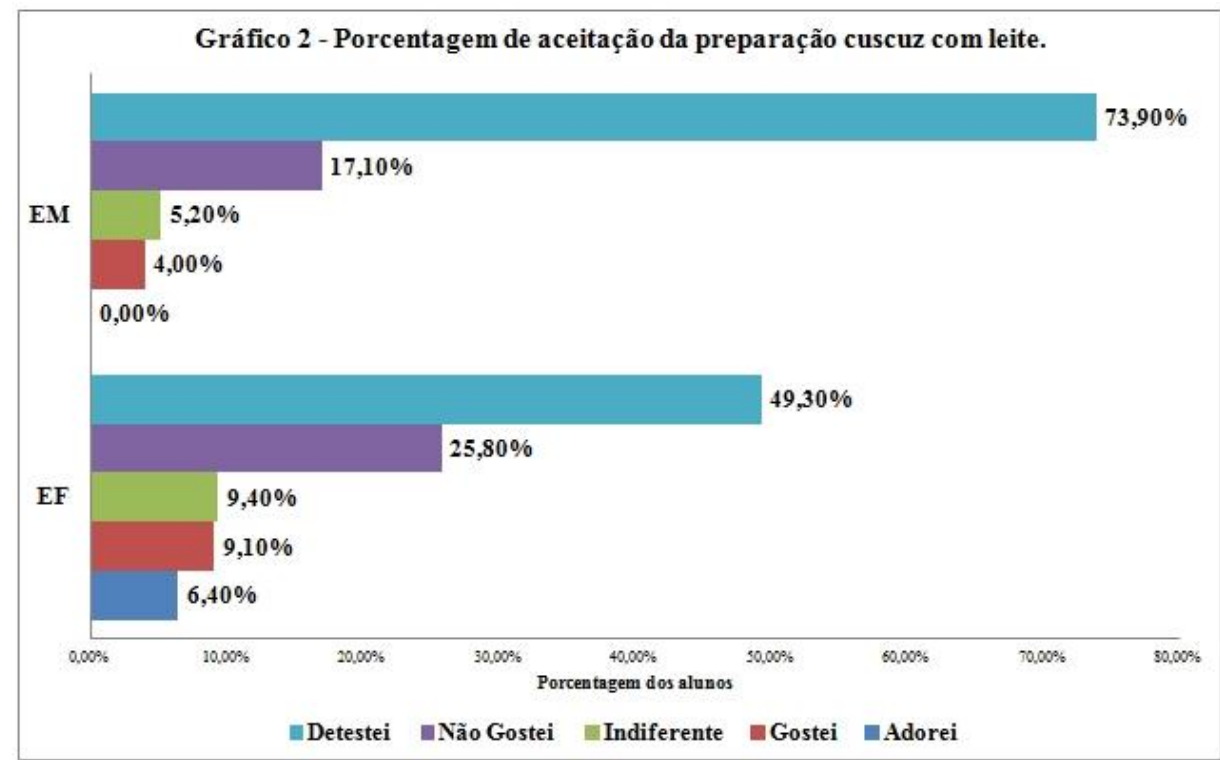

Quando questionados sobre o que mais gostavam nas preparações oferecidas, dos 248 alunos 
que responderam ao teste, na preparação macarrão com salsicha, 44,8\% disseram que gostam mais da salsicha; no cuscuz com frango, 39,9\% preferem ao frango; quanto ao achocolatado e pão com ovo, 55,7\% disseram achocolatado; no cuscuz com leite, 15,3\% responderam cuscuz; e por último, na feijoada, $14,5 \%$ apreciam mais o feijão. E quanto ao que menos gostavam nas preparações, no macarrão com salsicha, 25,8\% reclamaram da quantidade de óleo presente na preparação; no cuscuz com frango, $15,7 \%$ queixam-se da pele do frango que não é retirada antes do cozimento; quanto ao achocolatado e pão com ovo, 35,5\% não aprovam os ovos; no cuscuz com leite, 15,7\% responderam leite; e na feijoada, $8,9 \%$ não gostam da carne.

\section{Conclusões}

Com o presente estudo, pôde-se concluir que a alimentação escolar pode ser considerada de qualidade, já que os índices de aceitação tiveram bons resultados, no entanto é necessário que a escola inclua a aplicação do teste pra que possa avaliar a aceitação dos cardápios praticados frequentemente.

\section{Referências}

UNISEPE. (2015). Aceitação da merenda escolar entre alunos da Rede Estadual de Ensino da cidade de Amparo-SP. Saúde em Foco, Edição n: 07,/Ano: 2015, 281p.

BRASIL. (2009). Resolução/CD/FNDE no 38, de 16 de julho de 2009. Ministério Da Educação Fundo Nacional de Desenvolvimento Da Educação Conselho Deliberativo, 38(1), 1-63.

CECANE. Manual para aplicação dos testes de aceitabilidade no Programa Nacional de Alimentação Escolar - PNAE. UNIFESP, 2010, 56p.

CONRADO, S.; NOVELLO, D. Aceitação e Análise nutricional de merenda escolar por alunos da rede municipal de ensino do município de Inácio Martins/PR. Revista Eletrônica Lato Sensu, Ano 2, v. 1, p. 1-15, jul., 2007.

FNDE. Fundo Nacional de Desenvolvimento da Educação. Alimentação Escolar. Disponível em: <http://www.fnde.gov.br/programas/alimentacao-escolar/alimentacao-escolar-apresentacao>. Acesso em: 17 de agosto de 2016. 